\title{
Jazz Aesthetics Speak Loud in Allen Ginsberg's Howl: A Thematic Cultural Sketch
}

\author{
Marwan A. Hamdan
}

\author{
Assistant Profes sor, Al-Azhar University - Gaza, Palestine
}

\begin{abstract}
This paper investigates the style and devicesin which Allen Ginsberg evokes jazz and its aesthetics in his poetry, namely Howl to produce a modern to postmodern cultural phenomenon in the American culture. Howl exemplifies a sort of stylistic interdisciplinary and intertextuality in which Ginsberg fuses jazz musicality and techniques in its lines and stanzas. Thus, Ginsberg offers his audience a new fusion of artistic poetic experimentations with devices, techniques, and improvisation. Also, this paper tries to recollect relevant critiques relevant to postmodern aesthetic and thematic forces in the postmodern literature of Beat poets, such as Allen Ginsberg as long as he is one of the best who show such twining of jazz musicality and tempos in his masterpiece Howl.
\end{abstract}

Keywords- Allen Ginsberg, Jazz, Aesthetics, Howl, Interdisciplinarity, Culture, Intertextuality.

\section{INTRODUCTION}

Factually, music and literature are harmonious artistic twins that play an influential role in inspiring each other. For instance, Jazz, played on a variety of musical instruments, constitutes a set of sound performances and serves cultural purposes. It is the expression of African ethnic and cultural self-assurance and a sign for Cultural Revolution in America. The American Beat poet Allen Ginsberg renewed the genre of jazz poetry that reflects the impact of jazz musicality on the culture of mid-twenty century in America. Culturally, Beat poets produced this genre of popular poetry that adds a new flavor of interdisciplinarity to the cultural scene of America. Beat writers, like Ginsberg, admire jazz more as the style of jazz and bebop became inspirational in the 20th Century American culture. This essay seeks to examine the poetic texture of Howl (1955) that has jazz music as its driving theme and effect are framed in the same way; the process of its poetic and structural evolution. The sound techniques the poet uses in modeling Howl and the cultural and artistic effects of jazz musicality - an emergent cultural model - will be the focal interest of this paper.
Jazz musicality in poetry enriches the American popular culture, where Beat poetry fused with jazz delivers distinctive musicality, which helps "the performance and understanding of the poems" (Feinstein, 1997, p. 5). The sensitivity of Beat poetry draws a lot from the popular idioms and social language similar to that of jazz, all of which enrich the African-American culture. Moreover, Christine Recker asserts that jazz-related poetry in the 1920s implies "the all-encompassing influence of jazz music in American society" and that the poetic references to the jazz culture offer an incorporated element of this society (2008, p.101). Jazz and its musicality are "the language of the hipsters," and "Beards and bongo drums" were their ultimate symbols (Maynard, 1993, p. 201). In this regard, Ivor Griffiths argues that Ginsberg experienced jazz in poetry for his contemporaries were "crazy illuminated hipsters ... rising and roaming America, serious, curious, bumming and hitchhiking." Ginsberg's attitude toward America is clearly negative. Yet, he celebrates the emergent culture of people who went down the "American river... Dreams." Ginsberg invokes cultural phenomena and rituals to evoke a sense of a growing phenomenal subculture of the African-American. Howl works on acculturation in modern multicultural America. For example, people get to know and make use of African symbols, codes, music, and cultural practices. In this respect, Robert Kelly (1992) argues that music reshapes the African-American minorities as it is so intricately interwoven with their identity.

Aesthetically, there is a number of similitudes between jazz and Beat poetry in terms of rhythms, themes, tones and moods. The word beat is a common factor in both jazz and Beat poetry; it creates the spirit of expression. In this respect, the Beat generation launched the cultural innovation of fusing jazz, rock and roll, and bebop into poetry, which could "alter the United States into a more open, critical society" and culture (Luyten, 2012, p. 5). Then, Ginsberg's poetic method is haunted by prompt spontaneity of jazz music, adopting "the experimentalism of modern jazz" with an emphasis on spontaneity and the "innovative manipulation of form" (Watson, 2005). Thus, 
Ginsberg masters his "poetics of spontaneity or improvisation or meditation" (Singer, 2014). Ginsberg started reading his poems aloud in accordance with jazz accompaniment. In this light, Jack Kerouac compares Ginsberg's poetic style to that of jazz that "each comes on in waves of thoughts, not in phrases" (1992, p.57). For there is almost the same spontaneity in poetry and jazz, both forms have the ultimate flexibility and spontaneity that flame the emotions of the audience?

Beat poets try improvisation with jazz structures using "orthographic means" such as long spaces at the beginning of each line, or words drawn vertically in a poem to create speculation on jazz musicality (Feinstein,1997, p. 21). Also, juxtapositions of familiar "music and poetry," "word and tone," and "sound and poetry," recur with frequency in Howl. Critics discuss the relationship between jazz and Beat poets both culturally and aesthetically. For example, Ann Charters states that in jazz world of the "Bop generation" whose "Charlie Parker is a founder and Kerouac and Ginsberg are "the heir apparent" (1992, p.228). Clearly, Ginsberg's main use of the jazz model lies in his adaptation of the form of jazz to his poetic idioms to build emotional and rhythmic intensity as the musician does in jazz. Steven Paul Scher(1992) states that Ginsberg's use of "verbal music" shows the distinctive verbal musical patterns in Howl. In this respect, Kerouac argues that the structure of jazz poetry relies on "time being of the es sence in the purity of speech, sketching language is undisturbed flow from the mind of personal secret idea-words, blowing (as per jazz musician) on subject of image" (1992, p.58).

Mark Noferi (2004) states that jazz music succeeded to spread widely among diverse people motivating them to participate in its "cultural associations." Meanwhile, John Arthur Maynard concludes that beat poetry is "conceived specifically for jazz accompaniment and as such should be considered as spontaneously spoken oral messages" (1993, p. 99). Arguing that Ginsberg improvised his beat poems similar to jazz oration and musicality, Kerouac states that he could imagine that Ginsberg picks up the diction and musicality of jazz to create a cultural phenomenon that appeals to diverse audience (1992, p.57). Adapting musical sounds, rhythms, and techniques in Howl is similar to the jazz style, exerting an influential impact on his audience on reading Howl aloud.

\section{ALLEN GINSBERG'S HOWL SPEAKS JAZZ}

Relying on jazz patterns such as rhythm, alliteration, and meter to get poetic intensity, Ginsberg uses such devices in a similar way; fusing his own incantatory tone in Howl to create the desired effect of innovation. Ginsberg's poetic www.ijels.com cultural genius and innovation have inspired modern artistic performance in America where jazz dominates and imposes itself on Beat poets for the purpose of improvisation in literature. In this regard, Vernon Frazer (2018) refers to the impact of jazz and Beat poets on American culture, "Reading poetry to jazz ... has become a legitimate component of Beat and Post-Beat expression." Again, improvisations of jazz musicality allow to produce the forms of poetic lines that "coincide with their musical counterparts, the chords and the chord progression" of jazz and bebop (Pen, 2010). Ginsberg is the pioneer to artistically practice "the experimentalism of modern jazz" for his poetic method is "analogous to the approach taken by modern jazz pioneers" as a revolt against the previous forms of jazz and poetic musicality to develop and redefine them, states Joe Watson (2005). In his testimony, Kerouac explains the influence of the jazz improvisation on Beat poets,

Jazz and bop, in the sense of a tenor man drawing a breath and blowing a phrase on his saxophone, till he runs out of breath, and when he does, his sentence, his statement's been made ... That's how I therefore separate my sentences, as breath separations of the mind. (1992, p.57)

Therefore, such a new trend tempted the Beat writers to create assimilations with jazz music, first as a cultural development in the society, second as a technique to develop and enhance their forms and styles of writing. As a result, Ginsberg and Beat poets used to spend much time in jazz clubs "soothing the breeze and digging the music," states Mike Janssen (1994).

Aesthetically, jazz musicality and technique allow poetic variation and experimentation that embody intense and profound tone which produces jazz musicality. Ginsberg is the most notable Beat poet, whose rhythmic and artistic innovation never stops, adding more to modern American culture (Frazer, 2018). Ginsberg also experiments with jazz musicality as a way of twining or coupling based on his own understanding of multicultural scene that dominates America, in this sense, Sean Singer (2014) elaborates that Beat poets corresponded to African-American culture and that music has demolished social and cultural boundaries, "leapfrogging the guard of the black literary community." Moreover, Paul Berliner notes the corresponding tradition of jazz on creating music with the "metaphor" of language in which musicians use verbal expressions to assert es sential basics of musical mentality that drives expressions in jazz (1994, p. 192). In short, this statement refers to the cultural and artistic interdisciplinarity between Howl and jazz. 
Furthermore, a new trend of modern poetry accompanied by jazz music emerged as "jazz prosody," which uses instrumental versification to create both a new performance and a poetic musicality (Pen, 2010). In this light, Ginsberg consciously employs Kerouac's theory of "spontaneous bop prosody" to create a new style of poetic expression loosely based on the "metaphor of jazz," states Thomas Miller (1988, p. 66). Therefore, Ginsberg is deliberate in innovating his techniques in Howl. Luyten asserts that "under the influence of natural speech and an interest in experimental jazz and the organic prosody" of beat poets, Ginsberg came to invoke the style of "Spontaneous Prose" (2012, p.5).

Obviously, Ginsberg assimilates the aesthetics of poetry and jazz to establish the new jazz-poetry movement in San Francisco, "a city of jazz clubs, modem jazzmen, and cultural renaissance" (Kerouac, 1992, p.58). Commenting on the context of twinning jazz and poetry, Singer (2014) indicates that this city inspires poets to ponder things like jazz, poetry, and art with other people who see the world in the same way. Culturally, Luyten points out that "the nonconformist attitude could more likely be related to the cultural atmosphere surrounding rock artists" and the beat poets who created cultural coupling based on the mutual "inspiration and mimicking" (2012, p.30). This is what Ginsberg has done in absorbing jazz into Howl with a definite rhythmic style similar to drumming formed by the repetition of "who." Consequently, Ginsberg expanded his lines in Howl to include spontaneous waves of connected longer phrases showing his poetic skill of verbalizing the speech. Jazz is not strict, rather it is the process of envisage that enables poets to adopt its aesthetics. Such poets break the language into units similar to those of jazz sounds. One can say that jazz and the verbal interaction are alike with similar techniques and styles. Furthermore, Kelly emphasizes that "Jazz also worked ... as a way of reestablishing a kind of trust"(1992).

Poetically, Ginsberg experimentations with the length and rhythm of his phrases according to his own vision and sense based on jazz musicality. Beat poets experiment a lot with the rhythmic musicality of the poetic language fusing poetry with jazz. This fusion dominates Beat literature where it enables the poets to "synchronize the rhythms of the American vernacular with the rhythms of bop in masterly fashion" (Frazer, 2018). In this light, Preston Whaley (2004) refers to the purpose Ginsberg aspires to get from employing jazz music in Howl; it is to enable the poet to sustain self-consciousness. Whaley adds that Ginsberg's appropriation of jazz style is a way of resisting "the constraining power of the culture industries" and a way of www.jjels.com conforming to "the consumptive demands of the marketplace"(p. 135). As a result of this fusion and twining, there were great marks on the 1960scounterculture movement embodied in "the conservative American society and rejecting Conformism." Accordingly, Beat poetry expresses the precocious seeds of a new cultural emergence, states Luyten (2012, p.29).

Again, Beat poets rely on the process of improvisation to "transcend the mathematical precision of music and poetry" and to lead the poetic vibration and rhythmic form resulting in an artistic force (Pen, 2010). In this light, jazz aesthetic arises from the improvisation valid in jazz traditions and musical diction that poetically work on words and lines that compose the poem as a whole unite. Similarly, Howl fascinates critics who appreciate its fusion of cultural emergents such as jazz and its musical structures. Michael McClure (2006) argues that Ginsberg masters a process of metamorphosis from quiet and genius "bohemian scholar" to an "epic vocal bard." This process makes Howl similar to jazz musical structure and improvisation. Feinstein informs us that "jazz culture infused poetry with hip, Daddy-o vernacular, jagging the syntax and, often, the appearance on the page" (1997, p. 164). Thus, the evolution of jazz resulted in coupling unique musical types and tones, mainly from African culture. Ginsberg's view of jazz is based much on "cultural associations" that accompany Howl as the music itself (Tytell, 1976, p. 320). Supporting Tytell's view, Luyten insists that Howl is composed with free associations like "a collage" to create the impression that Howl "is no more than the chaotic outburst of a madman, arbitrarily arranging words" (2012, p.26).

Moreover, Ginsberg expresses his fascination with jazz and its artistic world of hipsters and with its "countercultural leanings" towards jazz unique poetics which enriches Ginsberg's jazz experience (Tytell,1976, p. 323). Accordingly, most Beat poets have used the ideas of jazz, creating a new poetic style characterized by the poetic stream of consciousness, and words flow out in vivid sounds. In this regard, Kerouac describes the phonetic performance of Beat poetry as writing with "No periods... but the vigorous space dash separating rhetorical breathing" exactly like jazz performance in expelling breaths between phrases (1992, p.57). Seemingly, jazz prosody in Howl allows us to identify and appreciate the artistic coupling of poetry and music, and it enables the poet to employ a sort of "typography and phonetics" to signify distinctive jazz sounds (Pen, 2010).

In fact, jazz music plays a great role in freeing poetry from any boundaries and limitations and provides remarkable space and driving force for the poetics, feelings, and

Page | 83 
tensions to release. Kelly (1992) also asserts that jazz has had some influence on American white poets associated with modernism for jazz is viewed as "low culture" and that jazz "had been created by the descendants of Africa." Ginsberg says in Howl, "Holy the groaning saxophone! Holy the bop/apocalypse! Holy the jazzbands marijuana/hipsters peace and junk and drums!" (Howl 27). Ginsberg's interest in jazz arises from his admiration of folk music and folk culture. He refers to the jazz culture and sounds in his poetry. He seems intimate to capture the rhythm and improvisation of the jazz musicality and spontaneity. In this way, Ginsberg elevates the AfricanAmerican jazz culture by referring to jazz playing and the brilliant Spaniard that moved to America and its culture, "Seeking jazz . . . and followed the brilliant Spaniard to converse about America and Eternity ... and to ship to Africa" (Howl 12).

Definitely, Howl has taken a new curve in Ginsberg's style in adapting jazz music to his poetics. Explaining the principles of the jazz-influenced Beat style, Ginsberg describes it as "First thought, best thought ...composing on the tongue" (To Eberhart,1976, p. 41). In addition, Ginsberg's Howl connects the rhythms of jazz delivers its ideas and themes in a spontaneous manner. Moreover, there are specific aspects of jazz musicality in Howl that is commonly built on fusing loose and rhythmic components of jazz. For example, Ginsberg says "what might be left to say in time come after death, and rose reincarnate in the ghostly clothes of jazz in the goldhorn shadow" (Howl 20). Thematically and structurally, "Jazz shaped the Beat aesthetics," manifesting acculturation phenomenon (Kelly, 1992).

Generally, Ginsberg employs jazz techniques in Howl as a model in two main ways. Steven Scher(1992) calls the first "word music," as an "imitation in words of the acoustic quality of music," in which poets generally use devices like alliteration, assonance, and consonance that resemble corresponding musical sounds (p 230). Second, Scher (1992) points to "scant singing" in which jazz vocalists use the sounds, which are unapprehendable and linguistically meaningless, to imitate jazz musical sounds and abstract human sounds to make musical units match the momentum of the performance (p.230). Thus, sound unit is fundamental in twinning poetry and music. These artistic cultural qualities make Howl similar to the aesthetics of jazz and musicality is its "tightness" and "spontaneity" (Raskin,2006, p. 139). For example, images of "negro streets," "angry fix," "paint hotels," "blind streets," and "hydrogen jukebox" are juxtaposed to communicate the poet's themes and ideas, similar to those always mentioned in jazz songs and chants.

www.jjels.com
Kelly (1992) pints out that The African American has had to survive by his or her sheer nerve and wit," a thing that appeals to Ginsberg as he quotes their images and codes in Howl.

In terms of cultural twining, Howl's poetics is similar to "the ethos of jazz, in its bubbling and fearless spontaneity" (Watson, 2005). Like jazz, Ginsberg leaps from one thematic image or motif to another with freedom and calls his jazz friends "negro streets," signifying an indication of his admiration with African-American legacy and culture,

I saw the best minds of my generation destroyed by madness, starving hysterical naked, dragging themselves through the negro streets at dawn looking for an angry fix, (Howl, p. 9)

Thus, Howl evokes jazz music and discourse, focusing on culture-based themes like isolation, depression, resentment, and madness. In this sense, Griffith's views jazz in poetry as a text in spoken and written style that signifies "a cultural icon of suppressed African Americans" and jazz music is another aspect of modern "alternative American Dream." Accordingly, Ginsberg mentions African-American cultural symbols manifested in jazz to refer to his own understanding and vision of modern American multiculturalism including the Blakcs who are, "angelheaded hipsters burning for the ancient heavenly" (Howl, p. 9).

Admittedly, jazz music inspires Ginsberg who in turn refers to it several times in Howl, in which both jazz music and hipsters have a spiritual quality, manifested in "the madman bum and angel beat in Time, unknown, yet putting down, here what might be left to say in time come after death" (Howl,p. 20). Here, Ginsberg's poetic and cultural juxtaposition and intertextuality of his own vocabulary and jazz's constitute a major significant twinning of jazz and poetry. Therefore, jazz for Ginsberg is the haunting source of his poetic musicality and intertextuality. This is why Ginsberg excels in composing poetic "spontaneous prose" in Howl (Patterson, 2004). Meanwhile, Ginsberg's Howl experiments with the "layering of melodic, harmonic, and rhythmic structures" that are similar to those in jazz musicality and composition (Muir).

Ginsberg's Howl embodies similar elements of jazz music for it has elongated lines to better suit similar length of the poetic breath. Jazz musicality is special in its intensity and spontaneity. Jazz cultural style is evident in Howl, "hallucinations! Miracles! Ecsatasies! ... Dreams! Adorations! illuminations! Religions!" (Howl 22). Here, the verbal poetic performance dominates the poem where the lines are connected spontaneously with each others with

Page | 84 
consistent musicality, pausing for breath in each line and launching another in another line. Ginsberg incorporates jazz to "attract a wider audience and bring poetry down to the level of the average jazz-club patron" (Patterson, 2004). Hence, Ginsberg's Howl helps to revive "the oral tradition and increased public awareness of modern poetry" (Frazer, 2018). In this regard, Ginsberg revolts against classical American poetry to raise it to a lofty intellectual and cultural level. Luyten argues that Ginsberg "rejected traditional poetic structure and traditional rhythmic patterns" and replaced them with "open, ecstatic expression of thoughts and feelings that were naturally poetic" (2012, p.25).

As an emergent cultural structure in a multicultural scene in modern America, jazz music introduces "a vital cultural lexicon" in the diction of Beat poetry (Watson, 2005) where, "Holy the groaning saxophone! Holy the bop apocalypse! Holy the jazz bands marijuana hipsters peace and junk and drums!" (Howl, p. 27). Accordingly, Ginsberg's Howl signifies a poetic aesthetic value towards beauty and harmonious structures; it uses "long, rambling lines, laden with awkward adjectives, do not aim for evocative brevity" to offer a modern distinctive poetic style and flavor (Watson, 2005). Ginsberg justifies his new rhythmic poetic form of long lines in which "ideally each line of Howl is a single breath unit... my breath is long that's the Measure, one physical and mental inspiration of thought contained in the elastic of a breath" (To Eberhart, 1976, p. 62). Clearly, Ginsberg intends to use such long lines to reveal that form is a vital poetic element that decides its improvisations, motifs, and influence. Moreover, Luyten indicates that "Jazz virtually became a guideline for literature," as clear in Howl, where Ginsberg's spontaneous poetry-like prose "replicated the typical structure of jazzand bebop improvisations" (2012, p.8).

Furthermore, Kerouac describes Ginsberg's poetic words and sentences as "musical, rhythmical constructions," that enable him to make the sequence of the sentences similar to the jazz music on hearing them (1992, p. 58). Thus, Ginsberg's Howl is a new mixture of the philosophical poetics and the writing style spontaneous jazz poetics to create a new style of expression based on the analogy of jazz with longsaxophonic chorus. Reading Howl accompanied by jazz music, we can decide that it has characteristics of "dithyrambic verse; raw and chaotic" (Carlson, 2007). For instance, Ginsberg cries in Howl, "foetid halls, bickering with the echoes of the soul, rocking and rolling in the midnight solitude-bench dolmen-realms of love" (Howl, p. 9). Here, Ginsberg's impressionistic tone with jazz musicality are evident and play a role in attracting www.jjels.com readers' attention to the rocking and rolling forces. Noticeably, Ginsberg starts the new line phrase continuing the rhythmic process from the previous line and giving the audience/readers the sense that he does not finish the first phrase yet.

Seemingly, Howl's rhythmic tone "speaks freely, expressing a discernable opinion in run-on sentences" with certain "lineation and parallel structure" (Carlson, 2007). Ginsberg says, "who lit cigarettes in boxcars boxcarsboxcars racketing through snow toward lonesome farms in grandfather night" (Howl, p. 12). Thus, these lines look similar to the jazz repeated one-tone phrases in constructing the idea of intense emotions. For Janssen, most Beat poetry has "a much looser, more syncopated rhythm, similar to jazz" (1994). Hence, jazz is very inspiring to Ginsberg as a celebrated Beat poet, who succeeds to mix both music and words together in an influential way. In this respect, Miller argues that jazz is more than music that it "became an attitude toward life, a way of walking, a language, and a costume" (1988, p.52). Ginsberg mentions that poetry and music are twins, and that "when the language got separated from song, the meters or verse forms were appropriate to song become lax" (To Eberhart,1976, p. 52). This means that Ginsberg finds the same quality and tendency to technically connect between music and poetry.

It is evident in Howl that Ginsberg releases his shouts on the holiness of the jazz where "marijuana hipster peace peyote pipes and drums" (Howl, p. 27). This emphasizes that Ginsberg is culturally fascinated with jazz stems and sounds. Similarly, Kelly (1992) admits that "Beat Movement was nothing more than the latest minstrel" that Charlie Parker was their "Buddha." Clearly, Ginsberg feels free to try new trend and technique of writing by replacing the short lines with jazz-influenced long lines; besides, he develops a "cataloguing style" and breaks the long lines into a "triadic ladder," states Noferi (2004). Thus, Ginsberg thinks of developing his style and technique to suit his new culture and to fuse jazz music in his poetry, but in his own unique voice and diction. To exemplify, Ginsberg's Howl releases the poet's breath and words to draw his tense feelings and emotions freely and without any delay and to convey his psychic world to other audience in a sort of assimilation in a language the people appreciate. For Ginsberg, the dominant "who" constitutes a refrain similar to refrains, moods, musicality, and spontaneity in jazz. It is then the cultural mood that led to the rise of jazz and its ramifications which "spearheaded the counterculture movement" in America (Luyten, 2012, p. 5).

Culturally, Howl suggests that jazz appeals to people, spiritually, intellectually and culturally. It exhibits a number

Page | 85 
of common jazz forms: the blues, boogie-woogie, and bebop. As such, Howl is "poetry in some way informed by jazz music" that identifies itself as verse that dominated early in the 20th Century (Feinstein, 1997, p.92). The verbal technique of Howl shows a series of improvisational phrases upon the same theme, pausing for breath and starting another. Similarly, Jazz musicians respond with their instruments as emotionally and culturally as possible to the words of the poem (Charters, 1992, p.17). In this sense, Maarten Luyten argues that both Beat poets and jazz musician and fans exchanged "cultural and philosophical influence" which resulted in having thematic cultural concerns manifested in their "values of spiritual and sexual liberation, demystification of drugs and antiestablishmentarianism" (2012, p.6).

Artistically, Ginsberg expresses his musical rhythmic long lines without sacrificing his own rhythmic style by relying on his own model of jazz. Ginsberg's model adopts the musical structure of jazz to achieve the same goal of its rhythm and sound. Based on fusing the musical structure of jazz upon Howl, Ginsberg transforms into a striking jazz poet in the cultural sense. In this light, Ian Muir argues that Ginsberg uses his own jazz-based poetic structures to influence his audience in accepting his poetic experimentation and jazz-like musicality and to "recognize order from chaos." Meanwhile, Ginsberg's Howl represents an experimental and improvisational technique that advocated a kind of free, unstructured composition in which the writer put down his thoughts and feelings without plan or revision - to convey the immediacy of experience-an approach that led to the production of much undisciplined and incoherent verbiage on the part of their imitators. (Maynard, 1993, p. 221)

In fact, Ginsberg experiments with his poetic techniques necessary for his own flavor and culture as "improvisation is a technique that challenges fixed form and diminishes the importance of form" (Watson, 2005). Accordingly, experimenting with improvisation enables Ginsberg to use rhythmic facilities that are fostered by jazz music, the "rhythms of jazz are more than metaphorically the rhythms of life" (Pen, 2010). No doubt, Ginsberg uses such rhythms to provide certain energies to his lines, creating a sort of parallels between the rhythms of jazz music and his improvised poetry, "the madman bum and angel beat in Time, unknown, yet putting down here what might be left to say in time come after death" (Howl, p. 20). Then, Ginsberg follows the breath of jazz to fuse the beat of the "madman bum and angel" in his lines. He composes lines hoping to be relevant "after death."

www.jiels.com
Remarkably, Ginsberg uses long lines that stem from his refusal of conventional metric forms. Rather, he integrates a fixed jazz base into his long lines and the injection of emotional intensity. Throughout Howl, Ginsberg's rhythmic technique is based on the repetition of "who." Accordingly, Ginsberg's Howl fused jazz rhythmic structures manifested in the "anaphora of the word "who" and in the rhythmic recurrence of the word "Moloch," which enabled Ginsberg coin his "archetypical rhythm" of Howl (Luyten, 2012, p. 8). Ginsberg's repeated use of "who." The repeated use of the word "who" in new lines gives the poem an aesthetic quality that generates a spiritual one. This "who" suggests the tone of anger at what the poet sees on daily cultural bases. By this repetition, he allows the natural rhythm of Howl to be heard, giving it the capability of building from "strophe to strophe" much as a "jazz solo" builds from "chorus to chorus," states Ginsberg (To Eberhart, 1976, p. 34). Ginsberg tries to show those "who" have the "best minds," employing jazz music that belongs to generators of this emergent culture. As such, Jazz enabled Ginsberg to communicate his ideas to diverse audience through his epic mural "Howl." Music kept diverse people "closer to the es sence" of thems elves (Kelly, 1992).

Furthermore, Ginsberg starts the "Footnote" in a way similar to the jazz techniques with longer lines and breaths. Joe Foreman mentions three movements to compare this part to a jazz piece. First, it is "the hot saxophone expressions," reminiscent of the jazz lines of Charlie Parker and Lester Young. Second, the movement of the short statements that reshape Howl's poetics. Finally, it is the "cool bluesy" and lyrical feelings which are similar to the moody music played by John Coltrane. To exemplify, Ginsberg says in Howl:

Moloch! Solitude! Filth! Ugliness! Aschans and unattainable dollars!

Children screaming under the stairways! Boys sobbing in armies!

. . . the whole boatload of sensitive bullshit. (Howl, pp. 21-22)

Here, jazz music is available and enables the poet to freely and eagerly express and dramatize his self in its cultural context. In this respect, Whaley refers to Ginsberg's "dramatizations" in these lines based on the flavor of the jazz musicality that influences the poem's rhythm and the way he used to read it (2004, p. 156).

Throughout Howl, Ginsberg uses jazz as an analogous model, since "music and literature are analogous, never identified, and the analogy breaks down when the readers draw specific rhythmic comparisons" (Scher,1992, p.229). In addition, Ginsberg associates imagery with jazz 
contributing to modern to postmodern Cultural Revolution. Recker states that Ginsberg's Howl "emulates the rhythmic imagery of a twenties cabaret in which jazz and dance, sound and sight, become one aesthetic response" (2008, p. 44). In this respect, Ginsberg makes a relevant hint in his footnote: "Holy the groaning saxophone! Holy the bop apocalypse! Holy the jazz bands marijuana hipsters peace and junk and drums!" (Howl, p. 27). Ginsberg artistically and culturally blends the rhythm of jazz music into Howl, who sang out of their windows in despair, fell out of the subway window, jumped in the filthy Passaic, leaped on negroes, cried all over the street, danced on broken wineglasses barefoot (Howl, p. 17)

Here, Ginsberg feeds his lines with the tone and spontaneity of jazz musicality, plainly mentioning dancing, singing, jazz, and whistling. Obviously, the actual music of jazz is only a part of the large scene around it that Ginsberg tries to find a sense of spirituality in the world around him. Besides, Ginsberg in "the supernatural darkness of cold-water flats [and] the tops of cities contemplating jazz" (Howl, p. 9) tries to confirm that jazz and its ramifications occupy much the same status for the Beats. Both offer modernized ways to achieve a higher spiritual connection with people based on the universal consciousness around them. Clearly, the impact of jazz is influential in Ginsberg's Howl, in which he cries "Holy the groaning saxophone! Holy the bop apocalypse! Holy the jazzbands marijuana hipsters peace peyote pipes \& drums!" (Howl, p. 9).

These lines culturally represent both thematic and stylistic manifestations of jazz in poetry in 20th century. They include rhyme, rhythm, alliteration, form, free verse, stream of consciousness, lyricism, improvisation, assonance, and imagery. Ginsberg intensively mentions jazz in Howl talking of those "who lounged hungry and lonesome through Houston seeking jazz or sex or soup" (Howl, p. 12). Culturally again, Ginsberg succeeds in using the technical performances and improvisations of jazz in Howl because he knew that it was a sort of an analogy. Apparently, he does not wholly recreate jazz rhythms, or jazz sounds, but the rhythms are his own, connected together loosely by the structure of jazz that he superimposed onto Howl, creating cultural and artistic intertextuality. Jazz and poetry constitute a phenomenon in modern literature, not only in America but also all over the world. Beat poets were inspired by a number of influences such as jazz, art, pop culture and philosophy, creating a sort of "a new and prophetic vision of modern life" and modifying the way in which "an entire generation of people see the world" (Raskin,2006, p.121). In this sense, Whaley asserts that www.ijels.com
Ginsberg elevates Howl as a "collective memory" of 1950s to protest against social and cultural class conflict and injustices that are new phenomena in the American crucible (2004, p. 201).

\section{CONCLUSION}

Ostensibly, Ginsberg's use of jazz is strongly and remarkably heard in Howl presented as a means for rhythm and poetics that interest him. Culturally, Ginsberg succeeded to present a piece of poetic verbal music based on jazz. Clearly, Ginsberg culturally and intertextually hopes to get a subjective response from the audience similar to what jazz does as he realized that music could soothe the soul, excite the emotions, and provide a sense of cultural identity. Moreover, he succeeded in twining his poetic stream-of-consciousness with jazz to create images and symbols of a modern to postmodern cultural achievement. Howl proves that cultural transmission is vital to maintain human qualities valid by intertextually referring to music, jazz, folk, media, drugs, among others. In this regard, Kelly (1992) argues that music is inseparable from the AfricanAmerican's identity, in which "The drum was a threat because it articulated cultural unity and communication."

No doubt, Ginsberg's poetry offers a wide range of structure to study the rhythmic form of jazz in poetry. Clearly, jazz aesthetics allows more improvisation and experimentation to examine the possibilities of artistic and appreciative reading of Ginsberg's jazz poetry. By such examination, critics can work on jazz poetry; its form and musicality that inspire a lot of readers and scholars. Listening to jazz music and chants, one can conclude that Ginsberg uses jazz in a more complicated, yet aesthetic, way through a variety of scales, tempos, moods, and styles. In fact, Howl is an example that encodes cultural values and rituals to unite generations by transmitting codes from African-American culture through music and jazz as part of its identity.

\section{REFERENCES}

[1] Berliner, Paul (1994). Thinking in Jazz: The Infinite Act of Improvisation. Chicago: University of Chicago Press.

[2] Carlson, Amber (2007). "The Beat Culture: Dionysian Influences in Allen Ginsberg's Howl." Retrieved on 8, July, 2018 from http://www.elance.com/samples/-beatculture-dionysian-influences-allen-gins bergs-howl.

[3] Charters, Ann ed. (1992). The Portable Beat Reader. New York: Viking.

[4] Feinstein, Sascha (1997). Jazz Poetry: From the 1920s to the Present. Westport, CN: Greenwood. 
[5] Foreman, Joe (2014). "Ginsberg's Technique in 'Howl'." Projects. Retrieved on 24 Sept. 2017 from http://www.cwl.utexas .edul slatin/20c/gh/technique.ht $\mathrm{ml}$.

[6] Frazer, Vernon (2016). "Extending the Age of Spontaneity to a New Era: Post-Beat Poets in America." Retrieved on 2 June 2018 from http://www.bigbridge.org/is sue10/fictvfrazer.htm.

[7] Ginsberg, Allen (2001). Howl and Other Poems. San Francisco: City Light Books.

[8] ... (1976). To Eberhart from Ginsberg. Lincoln: MA: Penmae P.

[9] Griffiths, Ivor (2006). "Ginsberg's Howl \& The American Dream." POETS. Retrieved on 24, July 2018 from http://www.blog.poet.me.uk/category/thebeats/gins bergs-howl-the-american-dream.

[10] Kelly, Robert (1992). "Jazz and Poetry: A Conversation." Georgia Review, 46(4), 645-654. Retrieved on 15 May, 2018 from http://www.english.uiuc.edu/maps/poets/g_1/komunya kaa/blackjazz.htm.

[11] Kerouac, Jack (1992). Essentials of Spontaneous Prose. New York: Penguin Books.

[12] Janssen, Mike (1994). "The Influence of Jazz on the Beat Generation." Litkicks. Retrieved on 8 March 2018 from http://www.rusc.net/ joan/brooklyn/Topics/JanssenOn Jazz.html.

[13] Luyten, Maarten (2012). “The Beat Generation's Influence on Rock and Roll." MA Thesis. Ghent University. Belgium. Retrieved on 12, July 2018 from www.english.ugent.be/file/47.

[14] Maynard, John Arthur (1993). Venice West: The Beat Generation in Southern California. New Brunswick: Rutgers University Press.

[15] McClure, Michael (2006). "Howl and the Howlers: Ginsberg Poem Fifty Plus Rears Later." Retrieved on 8 Sept. Web. Jan 22, 2018 from http://www.alsopreview.cogazeb/mes sages/2305/9866. htm.

[16] Miller, Thomas (1988). Allan Ginsberg. Boston: Twayne.

[17] Muir, Ian (2005). "Howl - A Musical Setting of the Poetry of Allen Ginsberg." Retrieved on 14, Feb. 2018 from http://www.steve-tromans.co.uk/Howl.html.

[18] Noferi, Mike (2004). "Jazz and the Beat Generation: The Musical Model in Literature." Retrieved on 21 Qct. 2018 from http://www.dla.utexas.eduldepts/ams/jazz/jazz3/noferi. html.
[19] Patterson, Eric V. (2004). "Blowing: Poetry Meets Music in the Writing of the Beat Generation." Empty Mirror. Retrieved on 8December 2017 from http://www.emptymirrorbooks .com/beat-writers-andjazz.html.

[20] Pen, Pauls (2010). "It Don't Mean a Thing (If It Ain't Got That Swing)": A Prosody of Jazz. WordPress. Retrieved on 8 March 2018 from http://paulspen.com/archives/17.

[21] Raskin, Jonah (2006). American Scream: Allen Ginsberg's Howl and the Making of the Beat Generation. North: California University Press.

[22] Recker, Christine (2008). Varieties of literary interpretations of jazz in American writings of the 1950s and 1960s. Munich: GRIN Verlag.

[23] Scher, Steven Pauled. (1992). Music and Texts: Critical Inquiries. Cambridge: Cambridge UP.

[24] Singer, Sean (2014). "Scrapple from the Apple: Jazz and Poetry." Poets.Org. retrieved on 14 March 2018 from http://www.poets.org/poetsorg/text/scrappleapple-jazz-poetry.

[25] Tytell, John (1976). Naked Angles: The Lives and Literature of The Beat Generation. New

[26] York: McGraw-Hill.

[27] Watson, Joe (2005). "Larkin, Ginsberg, Jazz and Modernism." Retrieved on 8 August 2017 from http://blogs.warwick.ac.uk/jwatson/entry/larkin_ginsb erg_jazz.

[28] Whaley, Preston (2004). Blows like a Horn: Beat Writing, Jazz, Style, and Markets in the Transformation of U.S. Culture. Cambridge: Harvard UP. 